\title{
Osseointegração clínica-radiológica do compósito hidroxiapatita-lignina entre implante metálico e tecido ósseo em coelho
}

[Clinical-radiographic osseointegration of hydroxyapatite-lignin composite between metallic implant and bone tissue in rabbit]

\author{
M.M. Martinez ${ }^{1,2}$, A.P.B. Borges ${ }^{3 *}$, L.G. Pompermayer ${ }^{3}$, E.C. Carlo ${ }^{1}$, L. M. Vilela ${ }^{1}$, D.M. Rates ${ }^{4}$, \\ G.O. Morato $^{4}$, R.B. Eleotério ${ }^{4}$, S.M.C.M. Bicalho ${ }^{5}$ \\ ${ }^{1}$ Aluno de pós-graduação - UFV - Viçosa, MG \\ ${ }^{2}$ Universidade de Córdoba - Córdoba, Colômbia \\ ${ }^{3}$ Departamento de Veterinária - UFV \\ Av. P.H. Rolfs, $\mathrm{s} / \mathrm{n}$ \\ 36570-000 - Viçosa, MG \\ ${ }^{4}$ Aluno de graduação - UFV - Viçosa, MG \\ ${ }^{5}$ JHS Laboratório Químico Ltda - Belo Horizonte, MG
}

\begin{abstract}
RESUMO
Para avaliar o compósito hidroxiapatita-lignina na osseointegração entre implante metálico e o tecido ósseo, foram utilizados 20 coelhos adultos, nos quais foi realizada uma falha óssea na face lateral proximal de ambas as tíbias. Na tíbia esquerda, introduziu-se, no canal medular, um pino intramedular de Schanz revestido com o compósito em sua parte rosqueada, após o preenchimento daquele com 1000mg do compósito. A falha cortical foi preenchida com o compósito. O mesmo foi feito na tíbia direita, porém sem a utilização do compósito, servindo como controle. A avaliação clínica baseou-se na deiscência, claudicação, sensibilidade dolorosa e circunferência tibial. Foram realizadas radiografias imediatamente após a cirurgia e aos oito, 30, 60, 90 e 120 dias do pós-operatório. A maioria dos animais apresentou evolução clínica normal. Nas radiografias do grupo tratado, houve decréscimo da radiopacidade no defeito e no espaço medular até tornar-se semelhante à do osso circunvizinho, quadro inverso ao do grupo-controle. Conclui-se que o compósito hidroxiapatita-lignina não mostrou indícios clínicos de rejeição e que o tecido visualizado na altura da falha óssea e ao redor do pino intramedular tinha radiopacidade semelhante à do osso circunvizinho, o que sugere que o material promoveu a integração com o tecido ósseo.
\end{abstract}

Palavras-chave: coelho, osseointegração, compósito, implante, hidroxiapatita, lignina

\begin{abstract}
This study evaluated a sinthetic hydroxyapatite-lignin composite for osseoingration between metallic implant and bone tissue. Twenty New Zealand rabbits were used. A defect was made a the proximal region of lateral surfaces of both tibias. An intramedullary pin was inserted in the medullary cavity of the left tibia after filling the cavity with 1,000mg of the composite and covering the thread part of the pin with the composite. The same procedure was made in control tibias without the composite. Clinical evaluation was based on inflammatory reaction, dehiscence, lameness, pain, and tibial circumference. Radiographs were made immediately after surgery and then on days eight, 30, 60, 90, and 120. Most of the animals presented normal clinical progression. Radiographies of treated group showed decrease in the defect and medullary cavity radiopacity to the same pattern of the surrounding bone, while the contrary happened in control group; but, in this group, the medullary cavity remained radioluscent at the last observation date. It can be concluded that the hydroxyapatite-lignin composite did not show clinical signs of rejection and that radiopacity of the tissue in the bone defect and surrounding the pin was similar to bone radiopacity, suggesting that the material promoted osseointegration.
\end{abstract}

Keywords: rabbit, osseointegration, composite, implant, hydroxyapatite, lignin

Recebido em 28 de março de 2008

Aceito em 12 de maio de 2009

Autor para correspondência (corresponding author)

E-mail: andrea@ufv.br 


\section{INTRODUÇÃO}

$\mathrm{O}$ afrouxamento de pinos em fraturas e os efeitos adversos sobre o tecido ósseo de algum biomaterial utilizado na fixação de próteses articulares levam à procura de alternativas no campo da implantologia e ortopedia veterinária e humana. Por esse motivo os implantes metálicos estão sendo revestidos com hidroxiapatita para conseguir fixação adequada no menor tempo possível (Furlong, 1998), mas as técnicas de revestimento encarecem os custos e, sobretudo, podem modificar a estrutura da hidroxiapatita e afetar sua biocompatibilidade.

A estrutura porosa da hidroxiapatita funciona como suporte passivo para a angiogênese, que leva fatores indutores da aposição óssea. Sua superfície porosa parece fornecer um substrato adicional à proliferação do tecido ósseo, permitindo a junção, proliferação, migração e expressão fenotípica de células ósseas, o que resulta em formação de novo osso, em oposição direta ao biomaterial. (Franco et al., 2001; Legeros, 2002; Perez et al., 2005; Vital et al., 2006).

A lignina é um componente da parede celular das plantas lenhosas que fornece a elas rigidez e atua como agente permanente de ligação entre as células. É um polímero complexo de elevado peso molecular, constituído de unidades de fenilpropano (Sjöström, 1993). Um compósito de hidroxiapatita sintética associada à lignina poderia unir a bioatividade da primeira com as propriedades ligantes celulares do último.

O objetivo deste trabalho foi avaliar a eficácia da hidroxiapatita associada à lignina (HAP-91 ${ }^{\circledR}-\mathrm{L}$ ) no processo de osseointegração entre um implante metálico e o tecido ósseo em coelhos adultos da raça Nova Zelândia, utilizando como recursos a avaliação clínico-cirúrgica e radiográfica.

\section{MATERIAL E MÉTODOS}

A metodologia deste trabalho utilizando animais experimentais foi analisada pela Comissão de Ética do DVT/UFV, aprovada em 03/05/2007 e protocolada como processo n. 58/2007. Utilizaram-se 20 coelhos machos da raça Nova Zelândia, com idades entre 10 e 12 meses e pesos entre 4 e $5 \mathrm{~kg}$. Os animais selecionados foram alojados em gaiolas individuais onde receberam uma dose única de $0,2 \mathrm{~mL}$ ivermectina ${ }^{1}$ a $1 \%$ pela via subcutânea, ração comercial duas vezes ao dia e água ad libitum.

O compósito foi constituído por $99 \%$ de hidroxiapatita sintética (HAP-91) ${ }^{2}$ e $1 \%$ de lignina, em forma de blocos de $4,5 \mathrm{~mm}$ de diâmetro e $200 \mathrm{mg}$ de peso. No pré-operatório, os animais foram mantidos em jejum hídrico e sólido de 12 horas e receberam 40.000UI/kg de penicilina $^{3}$ sódica e procainica, por via intramuscular, 30 minutos antes da indução anestésica. Posteriormente, foram sedados com levomepromazina ${ }^{4}$ na dose de $2 \mathrm{mg} / \mathrm{kg}$ e anestesiados com tiletamina e zolazepam ${ }^{5}$ na dose de $20 \mathrm{mg} / \mathrm{kg}$, ambos também pela via intramuscular. A região dos membros pélvicos, do terço proximal do fêmur até o terço distal da tíbia foi tricotomizada e desengordurada com éter. A anestesia dissociativa se complementou com a técnica epidural lombossacra utilizando-se lidocaína ${ }^{6}$ a $2 \%$ em associação com a epinefrina ${ }^{7}$ na dose de $1 \mathrm{~mL} / 4 \mathrm{~kg}$.

Em seguida, os animais foram posicionados em decúbito lateral direito. A abordagem cirúrgica, baseada na técnica descrita por Piermattei et al. (2006) para animais de pequeno porte e adaptada para coelhos, constou dos seguintes tempos cirúrgicos: incisão cutânea, tecido subcutâneo e fascia lata, parapatelar lateral desde o terço distal do fêmur até a diáfise proximal da tíbia, afastamento caudal da musculatura craniolateral da tíbia e exposição do periósteo. Logo após, realizou-se uma falha óssea na parte central da face lateral proximal da tíbia de, aproximadamente, $4 \mathrm{~mm}$ de diâmetro e profundidade suficiente para atingir o canal medular, com o auxílio de uma furadeira manual e broca de igual diâmetro. Em um mesmo animal, considerou-se a tíbia esquerda como tratada com o compósito HAP-91-L e a tíbia direita como controle.

\footnotetext{
${ }^{1}$ Mogimec 1\% ${ }^{\circledR}$ - Mogivet Produtos Agro Veterinários Ltda. São Paulo, Brasil.

${ }^{2}$ HAP $91^{\circledR}$ - JHS Laboratório Químico - Sabará, Brasil.

${ }^{3}$ Megacilin $^{\circledR}$ - Agener União - Embu-Guaçú, Brasil.

${ }^{4}$ Neozine ${ }^{\circledR}$ - Sanofi- Aventis - São Paulo, Brasil.

${ }^{5}$ Zoletil $50^{\circledR}$ - Virbac do Brasil - São Paulo, Brasil.

${ }^{6}$ Lidocaína $2 \%{ }^{\circledR}$ - Hipolabor - Sabará, Brasil.

${ }^{7}$ Adren ${ }^{\circledR}$ - Hipolabor - Sabará, Brasil.
} 
No grupo tratado foi introduzido pelo defeito cortical um pino intramedular de Schanz em aço F 138 de calibre de $1 \mathrm{~mm}$ com o intuito de descolar a medula óssea e irritar o endósteo por meio de movimentos de fricção repetitivos. Ainda, para favorecer a retirada da medula óssea, injetaram-se $10 \mathrm{~cm}$ de ar dentro do canal medular com o auxílio de uma seringa descartável e um cateter vênular de calibre 16, retirando-a na maior quantidade possível.

Em um recipiente, cinco comprimidos (1000mg) do compósito HAP-91-L foram amolecidos com solução fisiológica $0,9 \%$ numa relação de duas gotas por comprimido, resultando em massa de consistência fluida a qual foi introduzida no canal medular por meio de seringa e cateter calibre 16 (Fig. 4B). Parte dessa massa foi usada também para revestir a extremidade rosqueada do pino intramedular de Schanz em aço F 138 de diâmetro $2,5 \mathrm{~mm}$ para osso cortical. $\mathrm{O}$ pino foi medido, por meio da radiografia prévia da tíbia, desde o local determinado para se fazer o orifício até a epífise distal tibial, mantendo o comprimento de $7 \mathrm{~cm}$ em todos os animais. Logo após o pino ter sido cortado, ele foi introduzido pelo defeito cortical, e o seu calibre foi suficiente para ocupar, aproximadamente, $90 \%$ da cavidade medular. Em seguida, o mesmo compósito em forma de bloco (400mg) foi utilizado para preencher o defeito ósseo. O grupo-controle foi submetido aos mesmos procedimentos que o grupo tratado, com exceção da introdução do compósito de HAP-9 ${ }^{\circledR}$ - L no canal medular e no defeito cortical. Os tecidos incisados foram suturados de maneira rotineira.

No pós-operatório, os animais, submetidos à antissepsia da ferida cirúrgica, receberam morfina ${ }^{9}, 3 \mathrm{mg} / \mathrm{kg}$ a cada 12 horas, durante dois dias, pela via subcutânea, e $40.000 \mathrm{UI} / \mathrm{kg}$ de penicilina a cada 24 horas, durante dois dias, por via intramuscular, como analgésico e antibiótico terápico, respectivamente.

Para avaliação clínica, os animais foram observados por 15 dias. Avaliou-se o grau da claudicação na marcha, considerando como grau 0 quando não claudicava; grau I (claudicação moderada) quando se apoiava na planta do pé e

${ }^{8}$ Kalmedica Ltda. - Belo Horizonte, Brasil.

${ }^{9}$ Dolo moff injetavel 10mg/mL - União Química. - Pouso Alegre, Brasil. grau II (claudicação intensa) quando o apoio se dava em abdução, com sustentação do peso no membro contralateral e nos membros anteriores. Para avaliar a dor e o desconforto, procedeu-se à palpação da área operada com as seguintes observações: classificada como grau 0 , com ausência de dor e nenhum tipo de reação ao toque digital da área operada; grau I para animais que manifestaram dor caracterizada pela presença de alguns sinais como vocalização, dilatação pupilar e/ou aumento dos movimentos respiratórios, sem retração do membro pélvico após o toque digital; e grau II, quando, além das características de dor grau I, o animal puxava a extremidade ao toque digital e mostrava-se indiferente ao ambiente e sem interesse pelo alimento. Para determinar o aumento e a diminuição de edema, mediu-se a circunferência da região tibial com o auxílio de uma fita métrica no ponto médio entre as articulações do joelho e a articulação tibiotarsal. A deiscência da ferida e a secreção purulenta foram analisadas descritivamente e classificadas como ausente ou presente.

Os resultados da claudicação, da dor e circunferência da diáfise da região tibial foram interpretados comparando-se cada data de observação entre os grupos tratados e controle com a análise estatística realizada pelo teste de Friedman, significância fixada em $\mathrm{P}<0,05$. A evolução foi analisada comparando-se as datas dentro de cada grupo pelo teste de Dunn, também com significância estatística fixada em $\mathrm{P}<0,05$. O comportamento da claudicação e da circunferência da diáfise da região tibial para ambos os grupos foi representado por meio de uma linha de tendências.

Para análise radiográfica do defeito cortical e o redor do pino intramedular, foram realizadas radiografias da região tibial nas projeções mediolateral e craniocaudal, imediatamente após a cirurgia e aos oito, 30, 60, 90 e 120 dias do pós-operatório. A técnica radiográfica foi padronizada $(45 \mathrm{Kv}, 100 \mathrm{~mA}$ e $0,03 \mathrm{~s})$, e as radiografias analisadas quanto à radiopacidade, classificando-as em diferentes graus, sempre comparando os locais de implantação com o osso circunvizinho. Os resultados foram interpretados comparando-se cada data de observação entre os grupos tratados e controle com análise estatística realizada pelo teste de Friedman, significância fixada em $\mathrm{P}<0,05$. As datas dentro de cada grupo 
foram analisadas pela análise de variância, também com significância estatística fixada em $\mathrm{P}<0,05$.

\section{RESULTADOS E DISCUSSÃO}

Nos primeiros cinco dias pós-operatórios, todos os animais operados apresentaram claudicação e dor à palpação, começando um processo de regressão a partir do sexto dia, fato que difere de Borges (1998), Rezende et al. (1998), Franco et al. (2001) e Vital et al. (2006), que observaram apoio normal dos membros operados poucas horas após a cirurgia. Ao final do período de observação, todos os animais apresentaram recuperação do processo, com exceção de um coelho, que continuou claudicando, possivelmente devido à formação de um tecido granulomatoso em resposta ao náilon de sutura.
Não houve diferença perceptível entre os animais dos dois grupos, o que sugere uma possível biocompatibilidade do compósito, demonstrada também por Vital et al. (2006). A análise estatística indicou que não ocorreram diferenças entre o grupo-controle e o tratado. Comparandose as datas de observação dentro de um mesmo grupo, não houve diferença desde o primeiro até o quinto dia de avaliação, nem do sexto ao $15^{\circ}$ dia, de acordo com o teste de Dunn.

A tendência da claudicação dos membros pélvicos, tal como se mostra na Fig. 1, seguiu um comportamento linear decrescente em função do tempo, explicado pela seguinte equação linear: $y=-1,7679 x+25,276\left(R^{2}=0,9282\right)$, em que:

$\mathrm{y}=$ número de coelhos claudicantes; $\mathrm{x}=$ unidades em dias.

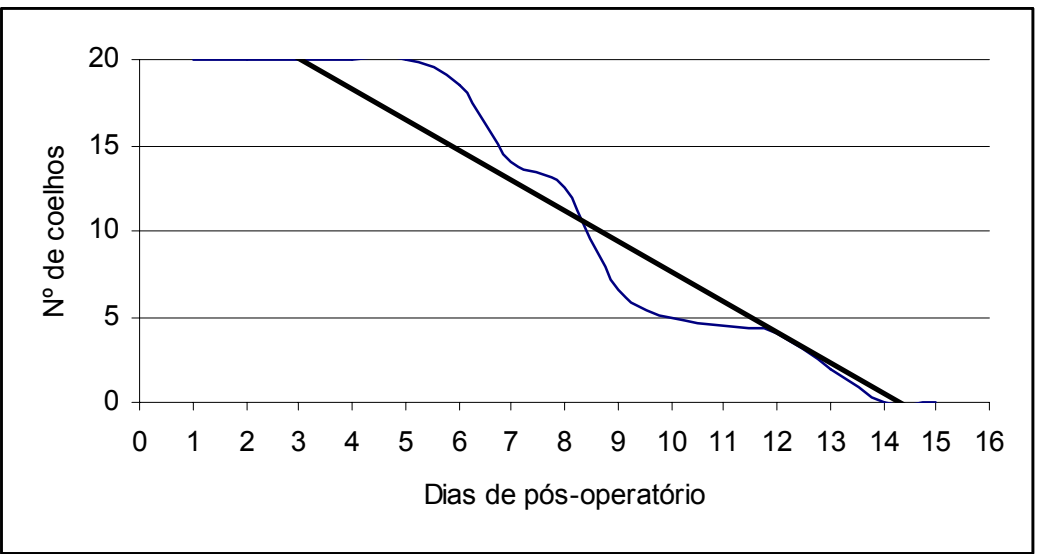

Figura 1. Linha de tendências da claudicação dos coelhos do grupo tratado com hidroxiapatita sintéticalignina e do grupo-controle, avaliados clinicamente durante 15 dias de pós-operatório.

O coeficiente de determinação indicou que este comportamento da claudicação dos membros pélvicos no período do tempo estudado, para os dois grupos, está explicado em $92 \%$ pela equação linear.

A tendência de o edema desaparecer ao final da avaliação deu-se em ambos os grupos e está de acordo com as observações clínicas de Borges (1998) e de Vital et al. (2006), que não verificaram diferença entre os grupos testados. Esse fato é sugestivo de que o compósito não influiu negativamente na resposta inflamatória. A similaridade química entre a hidroxiapatita e o tecido ósseo, provavelmente, contribuiu para isso.

A tendência da circunferência da região tibial, tal como se mostra na Fig. 2, seguiu um comportamento linear decrescente em função do tempo, explicado pela seguinte equação quadrática:

$y=0,0082 X^{2}-0,1849 X+9,0269\left(R^{2}=0,99\right)$, em que:

$\mathrm{y}=$ média da diáfise da região tibial em $\mathrm{cm}$; $\mathrm{x}=$ unidades em dias. 


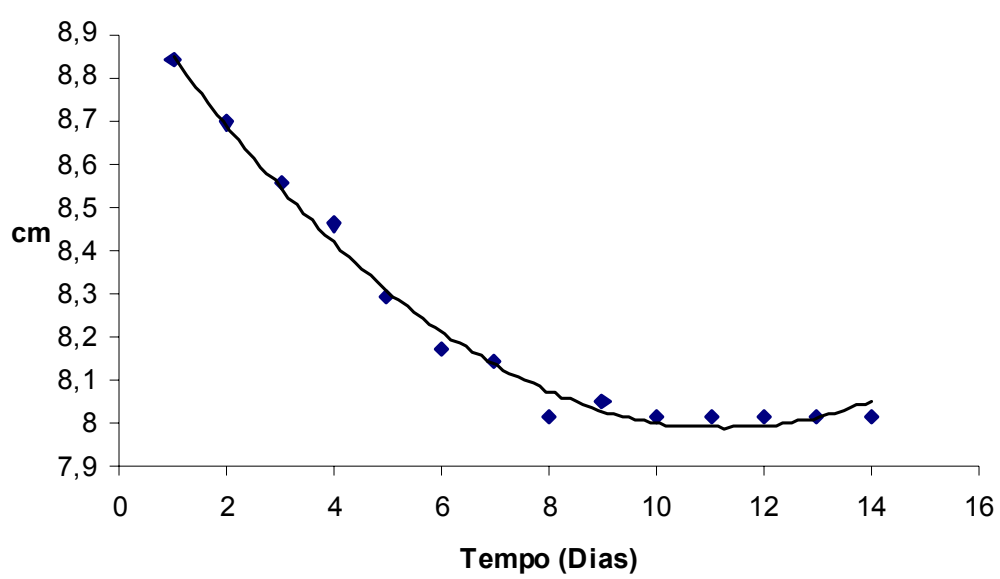

Figura 2. Linha de tendências da diáfise da região tibial $(\mathrm{cm})$ de coelhos do grupo tratado com hidroxiapatita sintética-lignina e do grupo-controle, avaliados clinicamente durante 15 dias de pósoperatório.

O coeficiente de determinação indicou que esse comportamento da circunferência da diáfise da região tibial no período de tempo estudado para os dois grupos, está explicado em 99\% pela equação quadrática.

Em apenas nove membros operados ocorreu deiscência da ferida $(22,5 \%)$, dos quais cinco $(55 \%)$ eram do grupo tratado e quatro do grupocontrole $(44 \%)$, sendo que, em todos eles, observou-se secreção purulenta procedente dos tecidos moles mais superficiais e com tendência a desaparecer ao final da avaliação clínica. Estes resultados assemelham-se aos obtidos por Vital et al. (2006) e diferem dos descritos por Moraes (2002) e Cehreli et al. (2003), que não observaram este sinal no pós-operatório. A ocorrência de deiscência da ferida, tanto em animais do grupo-controle quanto em animais do grupo tratado, se deveu, provavelmente, ao local da cirurgia, onde as tensões pelos movimentos de flexão e extensão, tanto na estática como na dinâmica, causaram a deiscência da ferida com posterior complicação infecciosa do local cirúrgico, e não a uma possível reação ao compósito. Um dos animais do grupo tratado apresentou reação do tipo corpo estranho, em resposta ao fio de sutura (náilon) utilizado, com a retirada do fio, houve regressão e cicatrização.

Os resultados radiológicos dos animais do grupocontrole obtidos imediatamente após a cirurgia revelaram radiopacidade menor do que o osso circunvizinho nas regiões do defeito tibial e na superfície ao redor do pino intramedular.
No grupo tratado (Fig. 3A), observou-se no defeito cortical, no mesmo período, radiopacidade maior do que a da cortical do osso circunvizinho, o que está de acordo com o descrito por Borges (1998), Duarte (2003), Rodriguez (2004) e Vital et al. (2006). A radiopacidade ao redor do pino intramedular (Fig. 3A) foi discretamente maior do que a da cortical do osso circunvizinho. Deve-se ressaltar que a distribuição do compósito foi maior na metade proximal do canal medular correspondente à diáfise proximal da tíbia.

Assim como o descrito por Yamamoto et al. (2000) e Vital et al. (2006), as radiografias obtidas imediatamente após o procedimento cirúrgico mostraram que o compósito foi bem colocado no osso receptor (Fig. 3A). Isso sugere que, apesar de ter ocorrido sangramento em todos os animais no momento da cirurgia, ele não foi suficiente para remover grande quantidade do compósito dos locais receptores, mas houve deslocamento médio proximal do compósito ao redor do pino, provavelmente favorecido por seu amolecimento com solução fisiológica. A não remoção da HAP- $91^{\circledR}-$ L pelo sangramento ocorrido no local da falha óssea foi, provavelmente, devido ao fato de ter-se usado uma forma sólida, em comprimido, o que facilitou sua colocação e ajuste no sítio receptor, obtendo-se preenchimento ótimo do defeito, sem lacunas entre o compósito e o osso. A estabilidade primaria inicial conseguida com o compósito assegura uma união efetiva com $o$ 
osso circundante, o que é um requisito à hora da colocação de próteses (Furlong, 1998).

Nas radiografias feitas aos oito, 30, 60, 90 e 120 dias no grupo tratado (Fig. 3), a radiopacidade do compósito diminuiu gradualmente com cada avaliação, até apresentar radiopacidade semelhante à do osso circunvizinho, em ambos os locais de implantação. Esse comportamento foi descrito por Borges et al. (2000) e Vital et al. (2006), que atribuíram essa diminuição de radiopacidade à invasão de tecido conjuntivo como parte do processo normal de reparação óssea. Deve-se considerar, ainda, que não houve alteração na densidade da hidroxiapatita, uma vez que seu número atômico não se altera. Entretanto, acredita-se que o crescimento de tecido conjuntivo e de tecido ósseo ao redor das partículas de hidroxiapatita com a evolução do processo contribui para a diminuição da radiopacidade do compósito (Rezende et al., 1998).

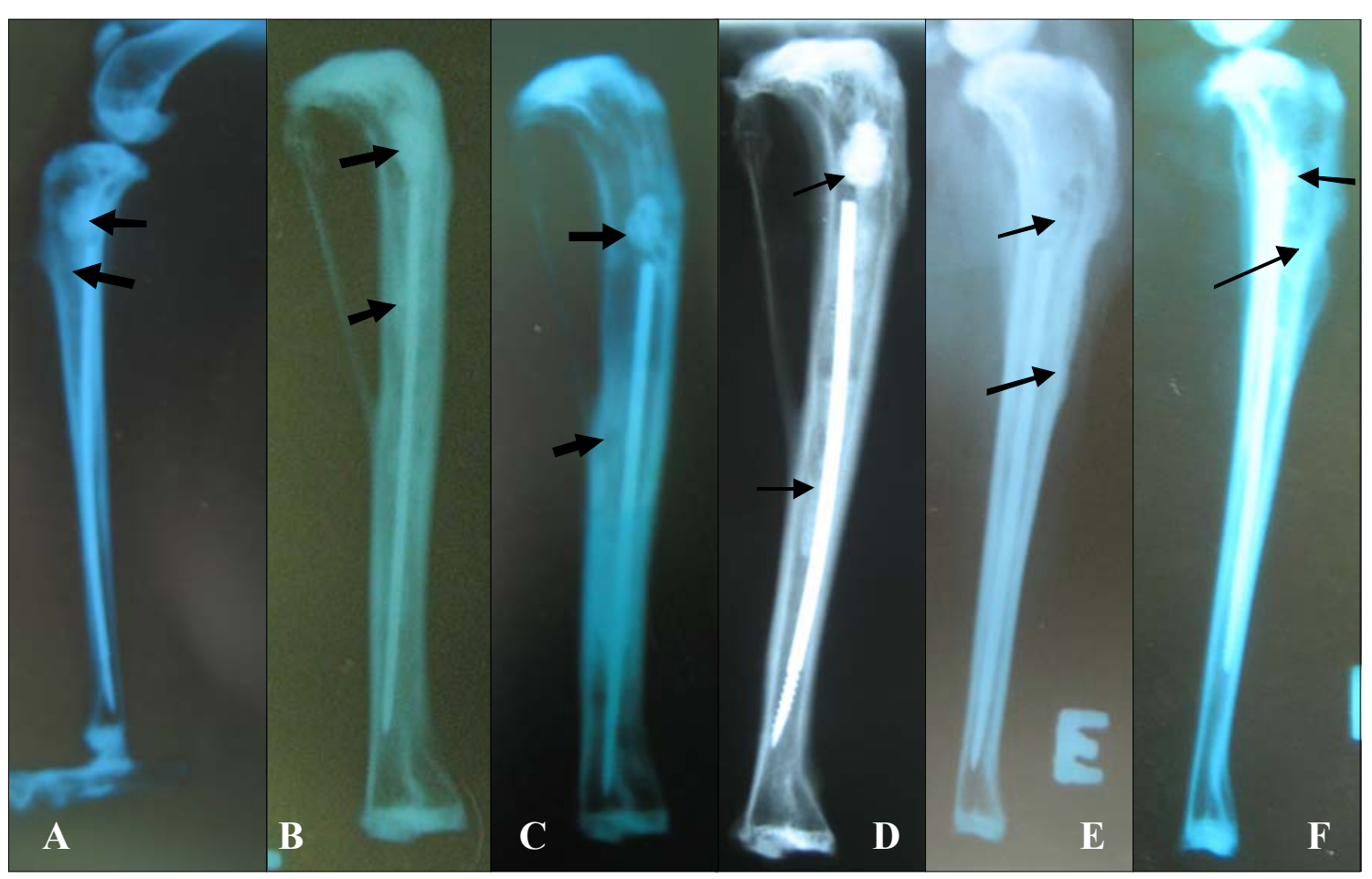

Figura 1. Radiografias da tíbia de coelhos do grupo tratado com hidroxiapatita sintética-lignina em projeção mediolateral. A, B e C: imediatamente após a cirurgia e aos oito e 30 dias do pós-operatório, respectivamente, nota-se radiopacidade maior ao ossocircunvizinho nos dois locais de implantação do compósito (seta larga); D, E e F: aos 60, 90 e 120 dias do pós-operatório, respectivamente, nota-se radiopacidade semelhante ao osso circunvizinho nos dois locais de implantação do compósito defeito cortical (seta fina).

Os dois locais implantados apresentaram semelhança com o osso circunvizinho, embora se tenha observado diferença na sua tonalidade de cinza, que é menor no canal medular. Esse fato pode ser devido à: 1- quantidade do compósito por unidade de área, que é menor no canal medular, fato favorecido por ter-se diluído com solução fisiológica para facilitar sua introdução no canal medular; 2- velocidade de absorção parcial, que talvez tenha sido mais rápida no canal medular, por ter maior quantidade de sangue por unidade de área; 3- a invasão de tecido mole à velocidade e quantidade maior junto com o processo normal de regeneração medular; 4- combinação das razões anteriores.

Com a observação detalhada em cada uma das datas de avaliação, aos oito dias a análise radiográfica dos defeitos tratados não mostrou sinais de redução de radiopacidade ou quaisquer sinais de reação óssea e de absorção do compósito, entretanto, ao redor do pino, 
observou-se diminuição da radiopacidade passando a ser discretamente maior ao osso circunvizinho (Fig. 4B).

No grupo-controle, para a mesma data (Fig. 4A), a falha permaneceu com radiopacidade menor ao osso circunvizinho porque, nesse mesmo período, o tecido presente na falha ainda não possuía radiopacidade suficiente para ser registrada no exame radiológico. Segundo Borges (1998) e Fehlberg (2001), em todo processo de reparação óssea, inicialmente, desenvolve-se tecido conjuntivo no foco da lesão, cuja radiopacidade é insuficiente para ser perceptível ao exame radiográfico, pelo fato de os constituintes do tecido neoformado possuírem baixo número atômico. A superfície ao redor do pino também teve radiopacidade menor que o osso circunvizinho (Fig. 4A).

Aos dias 30, 60, 90 e 120 de avaliação (Fig. 3C, $\mathrm{D}, \mathrm{E}, \mathrm{F})$, observaram-se diminuição progressiva da radiopacidade e do tamanho do compósito no defeito das tíbias tratadas e uma pequena mudança na forma de suas bordas, dando a impressão de remodelação. Esse fato foi observado por Duarte (2003) e Vital et al. (2006) e foi atribuído a um processo de absorção da hidroxiapatita na periferia do defeito. $\mathrm{Ou}$, ainda, isto pode sugerir a invasão de tecido conjuntivo precedendo a formação óssea na periferia do defeito após a absorção da hidroxiapatita (Fehlberg, 2001; Vital et al., 2006). No mesmo período de tempo, a radiopacidade ao redor do pino no grupo tratado assemelhou-se à do osso circunvizinho. No grupo-controle (Fig. 4), para o mesmo período de tempo (30,60, 90 e 120), observou-se, na falha óssea, aumento progressivo da radiopacidade até adquirir semelhança com a do osso circunvizinho. A radiopacidade ao redor do pino intramedular manteve-se menor do que a do osso circunvizinho (Fig 4).

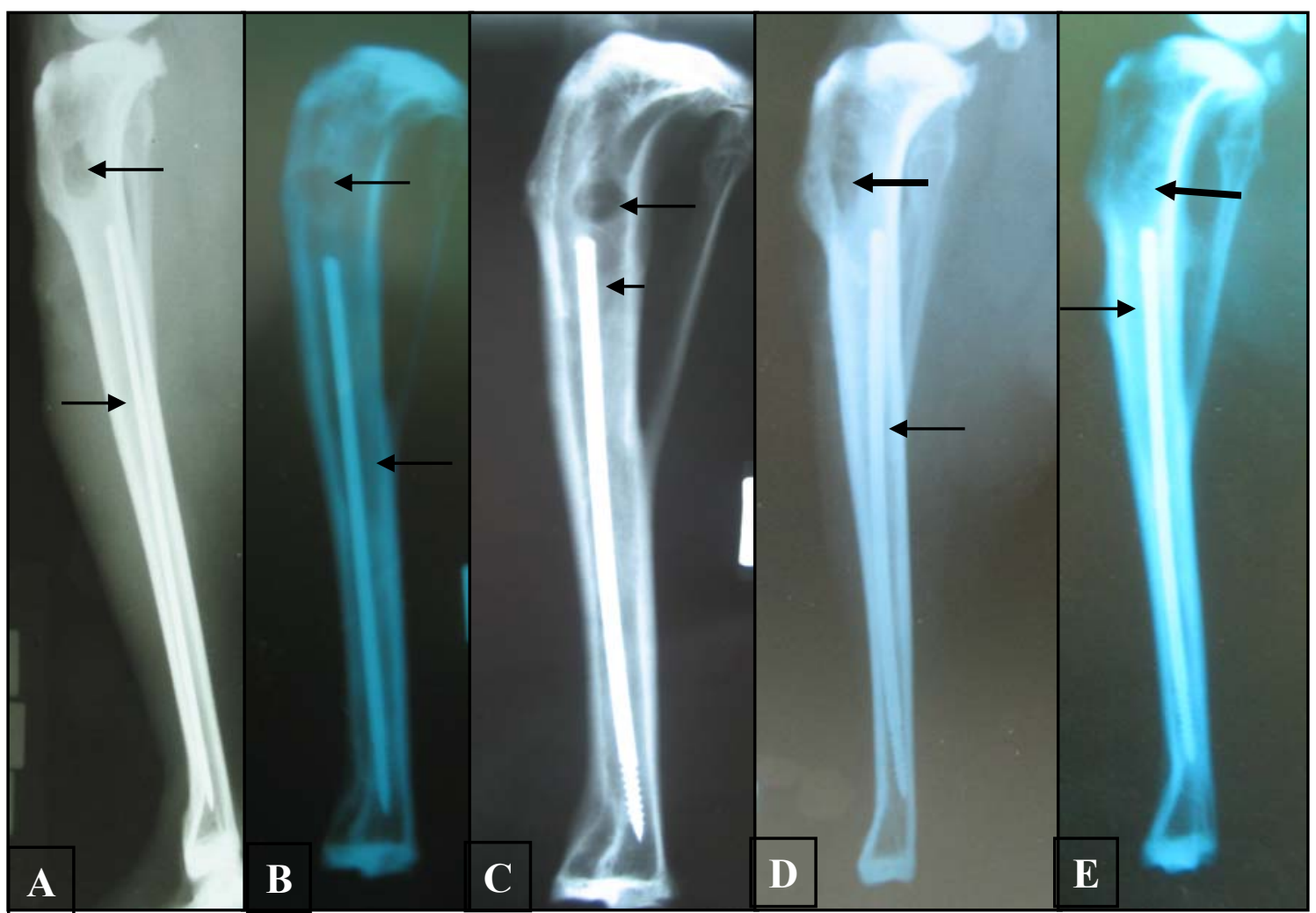

Figura 4. Radiografias da tíbia de coelhos do grupo-controle em projeção mediolateral. A, B e C aos oito, 30 e 60 dias após a cirurgia, respectivamente, nota-se radiopacidade menor tanto no defeito cortical como ao redor do pino intramedular (seta fina); D, E, aos 90 e 120 dias após a cirurgia, respectivamente, notar radiopacidade semelhante ao osso circunvizinho no defeito cortical (seta larga) e menor ao redor do pino intramedular (seta fina). 
Pode-se presumir que, para os dias 30, 60, 90 e 120, ocorreu crescimento ósseo em ambos os grupos, caracterizado pelo aumento da radiopacidade do defeito da periferia para o centro no grupo-controle, paralelamente à diminuição da radiopacidade do compósito no grupo tratado.

No teste de Friedman e ao comparar as datas de estudo entre os grupos, observou-se que somente aos 90 e 120 dias de avaliação não houve diferença significativa na radiopacidade do defeito cortical $(\mathrm{P}>0,05)$. Esse fato indica que a radiopacidade do defeito para esses dias de avaliação entre ambos os grupos foi semelhante e, possivelmente, deveu-se ao ganho de radiopacidade do defeito cortical controle, pelo processo reparativo ósseo, e ainda evidencia que o grupo tratado perdeu radiopacidade na medida em que o compósito foi absorvido e invadido por tecido de menor radiopacidade.

Na análise do teste de Friedman e ao se comparar as datas de estudo entre os grupos, observou-se diferença significativa na radiopacidade da superfície ao redor do pino intramedular $(\mathrm{P}<0,05)$, exceção da última avaliação. Esse fato indica que o espaço do canal medular ocupado pelo compósito manteve radiopacidade sempre maior ao ser comparado com o espaço correspondente no grupo-controle, exceto aos 120 dias de avaliação.

$\mathrm{Na}$ análise estatística entre datas para o defeito cortical e a superfície ao redor do pino intramedular do grupo tratado, não houve diferença $(\mathrm{P}>0,05)$, de acordo com a análise de variância, apesar de observarem-se diferenças biológicas caracterizadas pela diminuição de radiopacidade com a evolução do tempo, de acordo com os escores de classificação.

Conclui-se que o compósito de hidroxiapatita sintética e lignina não mostrou indícios clínicos de rejeição e que o tecido que cresceu na altura da falha óssea e na superfície ao redor do pino intramedular implantado, ao final do experimento, tinha radiopacidade semelhante à do osso circunvizinho, o que sugere que o material promoveu a integração com o tecido ósseo.

\section{AGRADECIMENTOS}

Os autores agradecem ao laboratório JHS, por proporcionar o compósito testado, e à Universidade de Córdoba - Colômbia.

\section{REFERÊNCIAS BIBLIOGRAFICAS}

BORGES, A.P.B. O efeito da hidroxiapatita sintética na regeneração óssea de defeito provocado experimentalmente no terço proximal da tíbia, de cães (Canis familiares): estudo clínico-cirúrgico, radiológico e histológico por microscopia de luz e microscopia eletrônica de retrodispersão. 1998. 112f. Tese (Doutorado) Escola de Veterinária, Universidade Federal de Minas Gerais, Belo Horizonte.

BORGES, A.P.B.; REZENDE, C.M.F.; RIBEIRO, M.F.B. et al. Hidroxiapatita sintética como substituto ósseo em defeito experimental provocado no proximal da tíbia de cão: aspectos à microscopia de transmissão. Arq. Bras. Med. Vet. Zootec., v.52, p.616-620, 2000.

CEHRELI, M.C.; SAHIN, S.; KESENCI, K. et al. Biological rections to a poly (L-lactide)hydroxiapatite composite: A estudy in canine mandible. J. Biomat. Appl., v.17, p.265-276, 2003.

DUARTE, T.S. Osseointegração da hidroxiapatita sintética no processo alveolar da mandíbula de cães. 2003. 58f. Tese (Mestrado) Departamento de Medicina Veterinária, Universidade Federal de Viçosa, Viçosa.

FRANCO, K.L.; BORGES, A.P.B.; VILÓRIA, M.I.V. et al. Hidroxiapatita sintética pura, hidroxiapatita associada ao colágeno e hidroxiapatita sintética associada ao lipossoma como substitutos ósseos em defeitos provocados na tíbia de cães: aspectos da osteointegração à microscopia de luz transmitida. Arq. Bras. Med. Vet. Zootec., v.53, p.431-436, 2001.

FEHLBERG, A.F. Hidroxiapatita sintética na regeneração da falha óssea provocada em fratura completa de terço intermédio de tíbia imobilizada pela fixação percutânea em cães. 2001. 42f. Tese (Mestrado) - Departamento de Medicina Veterinária, Universidade Federal de Viçosa, Viçosa. 
FURLONG, R. The application clinical behaviour of hydroxyapatite ceramic in prosthetic coatings. $J$. Bone Jt. Surg. Br., v.80, p.31-32, 1998.

LEGEROS, R.Z. Properties of osteoconductive biomaterials: calcium phosphates. Clin. Orthop. Relat. Res., v.395, p.81-98, 2002.

MORAES, P.C. Biocompatibilidade e comportamento do cimento de fosfato de cálcio, reforçado com diferentes tipos de fibras, implantado no rádio de coelhos. 2002. 73f. Tese (Mestrado) - Faculdade de Ciências Agrárias e Veterinárias, Universidade Estadual Paulista, Jaboticabal.

PÉREZ, Á.; ORTEGA, V.; MESEGUER, L. et al. Implante óseo de la espuma de hidroxiapatita-09, estudio experimental en conejos. Rev. Esp. Patol., v.38, p.14-20, 2005.

PIERMATTEI, D.L.; FLO, G.L.; DECAMPO, C.E. Handbook of small animal orthopedics and fracture repair. 4.ed. St Louis: Saunders Elsevier, 2006. p.139-140.

REZENDE, C.M.F.; BORGES, A.P.B.; BERNIS, et al. Aspectos clínico-cirúrgicos e radiográficos da hidroxiapatita sintética na diáfise proximal da tíbia de cães. Arq. Bras. Med. Vet. Zootec., v.50, p.537545, 1998.

RODRIGUEZ, A.I.R. Avaliação da reconstituição óssea do rádio de cadelas submetidas ou não a ovariossalpingohisterectomia, utilizando hidroxiapatita com alandronato e hidroxiapatita com colágeno (avaliações densitométricas e radiográficas). 2004. 58f. Tese (Mestrado)Faculdade de Ciências Agrárias e Veterinárias, Universidade Estadual Paulista, Jaboticabal.

SJÖSTRÖM, E. Wood chemistry: fundamentals and applications. San Diego: Academic Press, 1993. 293p.

VITAL, C.C.; BORGES, A.P.B.; FONSECA, C.C. et al. Biocompatibilidade e comportamento de compósitos de hidroxiapatita em falha óssea na ulna de coelhos Arq. Bras. Med. Vet. Zootec., v.58, p.175-183, 2006.

YAMAMOTO, T.; ONGA, T.; MARUI, T. et al. Use of hydroxiapatite to fill cavities after excision of bening boné tumors. J. Bone Jt. Surg., v.82-B, p.1117-1120, 2000. 